\title{
Derivation of a Proteus mirabilis Converting Phage for Ampicillin Resistance
}

\author{
By J. N. COETZEE \\ Department of Microbiology, University of Pretoria, Republic of South Africa
}

(Received 17 August 1976)

\begin{abstract}
SUMMARY
A lysate of phage $5006 \mathrm{M}$ was prepared on Proteus mirabilis PM5006 which harboured the plasmid P-lac to which the ampicillin resistance gene of $\mathbf{R}$ plasmid $\mathrm{RP}_{4}$ had been transposed. This lysate transduced the ampicillin resistance marker to PM5006 at a frequency of $5 \times 10^{-10}$ per plaque-forming unit adsorbed. Five independently derived transductants were induced with ultraviolet light and yielded lysates which transduced ampicillin resistance at frequencies greater than unity. The lysates contained a majority of particles which formed small, slightly hazy plaques on PM5006. The other plaque-type was larger with a turbid centre and resembled the wild-type plaque. On replication of the phage titration plates to ampicillin agar, the bacterial growth in all the small plaques grew on the agar (plaque-replica transductants) whereas only that of a small and variable proportion of the large plaques did so. Low dilution titration plates (with many plaques) gave more replica transductants than could be accounted for by plaque counts, whereas with higher dilution plates the two tallied perfectly. The marker was unstable during lytic growth and, in a further cycle of growth of phage from small plaques, the proportion of wild-type plaque-forming particles increased and was accompanied by a reduction in the proportion of the large wild-type plaques which replicated to ampicillin agar. The marker translocated from the phage to another $\mathbf{R}$ plasmid, and also inserted into the chromosome of PM804 and a newly discovered host PM98, rendering some transductants of these strains auxotrophic.
\end{abstract}

\section{INTRODUCTION}

Specialized transducing variants capable of transducing certain antibiotic resistance markers at high frequencies have been described for phage P22 (Dubnau \& Stocker, 1964; Watanabe et al., 1972; Tye, Chan \& Botstein, 1974), phage lambda (Dempsey \& Willetts, 1976), phage epsilon (Kameda et al., 1965), phage 5006M (Coetzee, 1974, 1975a, 1976b) and phage PL25 (Coetzee, 1975b). These variants were defective in certain phage functions and did not form plaques on single infection. Plaque-forming variants of phage PI capable of transducing, in single infection, chloramphenicol resistance (Kondo \& Mitsuhashi, 1964) and kanamycin resistance (Goldberg, Bender \& Streicher, 1974) have been described and phage lambda plaque-forming particles were selected which transduced chloramphenicol resistance (Scott, I973; Gottesman \& Rosner, 1975) or resistance to kanamycin (Berg et al., 1975). A PI related phage (Chesney \& Scott, 1975), фamp, was isolated from a strain of Escherichia coli which, on single infection, conferred ampicillin resistance on bacterial hosts (Williams Smith, 1972). As part of a series of experiments (unpublished) in connexion with transduction of the lactose-utilizing property to Proteus, the ampicillin resistance marker of plasmid RP4 (Datta et al., I97I) was transposed (Hedges \& Jacob, 1974) on to P-lac (Falkow et al., 1964). This was done by transduction of the $\mathrm{R}$ factor marker to a strain of Proteus which carried P-lac as resident. In this paper, the formation of a plaque-forming variant of 
Table I. Bacteria, plasmids and phages

\author{
Bacteria \\ Proteus mirabilis \\ PM5006
}

PM5006arg-I PM5006trp-I PM5006lys-I PM5006str-r PM5006( $\overline{\text { SuSK }}) \dagger$ PM804

NHI

PM98

\section{Escherichia coli J62-I}

Plasmids and hosts PM5006(P-lac $\overline{\mathbf{R P 4}}) \dagger$

PM5006(RS-a)

Bacteriophages 5006M.PM5006

5006MHFTsusk
Properties*

Host for phages. Cryptically lysogenic for phage 5006M. Resistant to T

Auxotrophs of PM5006

Spontaneous mutant resistant to $\mathrm{S}$ at $\mathrm{I} \mathrm{mg} \mathrm{ml}^{-1}$

Transductant of PM5006 by phage 5006MHFTsusk

Cannot be shown to adsorb phages $5006 \mathrm{M}$ or 5006MHFT $a k$, but may be transduced to AK resistance by the latter phage

Mutant of strain $\mathrm{N}$ which plates phage 5006 M.PM5006 with an efficiency of $5 \times 10^{-1}$

Isolated locally from human faeces. Swarms form lines of demarcation with those of PM5006, PM804 and NHI

$\mathrm{F}^{-}$lac, pro, his, trp, nal-r mutant of $E$. coli KI2

Ferments lactose and A resistant. Marker A of RP4 integrated in P-lac. Co-transfers markers by conjugation. Produced by transducing RP4 with phage $5006 \mathrm{M}$ into PM5006 with P-lac as resident. This particular organism was produced by transferring the markers by conjugation to $\mathrm{J} 62-\mathrm{I}$ and then back to PM5006 with counterselection for donor with T

W incompatibility group plasmid with markers $\mathrm{S}, \mathrm{C}, \mathrm{K}, \mathrm{Su}$

Cryptic prophage of PM5006. Lysate produced by lytic infection of PM5006. On lysogenization converts hosts PMI3 and PM5006 to non-adsorption of homologous phage. Generalized transducing for PM5006. Circularly permuted genome. Serologically identical to phages 34 and 5006MHFTsusk

High frequency transducing for $\mathrm{S}, \mathrm{Su}$ and $\mathrm{K}$
Reference

Coetzee \& Smit (1970)

Krizsanovich (1973)

Coetzee (1974, 1975 $a, b$, I976b)

Coetzee (1974)

Coetzee (1974)

Coetzee (1976b)

Coetzee $(1976 a, b)$

Coetzee \& Smit (1969)

This paper

Clowes \& Hayes (1968)

Coetzee (unpublished)

Datta \& Hedges (1972)

Coetzee \& Sacks (1960)

Coetzee (1974, 1976b)

Krizsanovich (1973)

Van Rensburg (1970)

Coetzee $(1976 b)$

* Symbols designate resistance to: A, ampicillin; C, chloramphenicol; K, kanamycin; S, streptomycin; $\mathrm{T}$, tetracycline; Su, sulphonamide.

$\dagger$ Superior line indicates that markers were transduced into the strain.

Proteus mirabilis phage $5006 \mathrm{M}$ which transduces the ampicillin resistance marker of $\mathrm{RP}_{4}$ is described.

\section{METHODS}

Bacteria, plasmids and phages. These are listed in Table I.

Media. Nutrient broth was Oxoid no. 2, code CM67. Nutrient agar was the same broth solidified with $\mathbf{I} \cdot 2 \%(\mathrm{w} / \mathrm{v})$ Difco agar. MacConkey agar was from Difco, and minimal medium was that of Grabow \& Smit (1967). When lactose utilization was the selected marker in transduction experiments, the minimal medium contained $0.3 \%(\mathrm{w} / \mathrm{v})$ lactose and $0.01 \%(\mathrm{w} / \mathrm{v})$ tetrazolium chloride (Grabow, 1972) instead of glucose. Incubation temperature was $37^{\circ} \mathrm{C}$. 
Drugs and antibiotics. Chloramphenicol, kanamycin, nalidixic acid, tetracycline and streptomycin were used at $50 \mu \mathrm{g} \mathrm{ml}^{-1}$. Streptomycin was also used at $\mathrm{I} \mathrm{mg} \mathrm{ml} \mathrm{m}^{-1}$, and ampicillin was used at $30 \mu \mathrm{g} \mathrm{ml}^{-1}$ unless otherwise stated.

General phage techniques. These were described by Adams (1956) and Coetzee (1974). Freeze-dried phage 34 antiserum (Coetzee \& Sacks, 1960) with a neutralization constant $(K)$ of $180 \mathrm{~min}^{-1}$ against phage 5006MHFTsusk was used.

Conjugal transfer of plasmids and preparation of lytic phage lysates. Methods were as described by Coetzee et al. (1973).

Phage adsorption. This was as described by Coetzee (1976a).

Ultraviolet induction of phage. This was as described by Coetzee (1974) with the modification that strains were grown overnight in broth containing ampicillin.

Concentration of phage lysates. The method described for P22 by Yamamoto \& Alberts (1970) was used.

Transduction and replica-screening technique for detection of HFT phage. Transductions were done according to the Millipore membrane filter technique of Coetzee (1974) with the following modifications. For transduction to prototrophy, the adsorption mixture was filtered with a large excess of sterile saline before placing membranes, with impinged cells, on the minimal medium. In all experiments involving minimal medium, plates were incubated for $60 \mathrm{~h}$ before results were read. For transductions to kanamycin or streptomycin resistance, membranes with impinged cells were incubated on nutrient agar for $2 \mathrm{~h}$ before transfer to selective media; for ampicillin resistance, membranes were incubated for the same period, unless stated otherwise. Phage titration plates to be replicated to antibiotic agar were chilled for about $2 \mathrm{~h}$ at $4{ }^{\circ} \mathrm{C}$ to harden the top layer of agar.

\section{RESULTS}

Preparation of phage 5006M.PM5006(P-lac $\left.\overline{\mathrm{RP}_{4}}\right)$ and transduction of markers to $\mathrm{PM} 5006$

The lysate had a titre of $5 \times 10^{10}$ plaque-forming units (p.f.u.) $\mathrm{ml}^{-1}$. Only the ampicillin resistance marker was transduced to PM5006 at low frequencies (Table 2). These transductants are named PM5006( $\overline{\mathrm{A}})$.

Properties of transductant strains $\mathrm{PM} 5006(\overline{\mathrm{A}})$. Transductants showed conversion to homologous phage non-adsorption (Coetzee, 196I) and overnight cultures grown in nonselective broth contained about $30 \%$ of ampicillin-sensitive clones. The possibility that transductants were heterogenote-like for the ampicillin resistance marker (Luria, Adams \& Ting, 1960) was investigated by ultraviolet induction of five independently isolated transductants.

Properties of lysates derived by ultraviolet induction of PM5006( $(\overline{\mathrm{A}})$. Lysates had titres of $\mathrm{I} \times 10^{8}$ to $8 \times 10^{8}$ p.f.u. $\mathrm{ml}^{-1}$ and between 85 and $95 \%$ of plaques produced by each lysate were about $\mathrm{I} \mathrm{mm}$ in diameter and hazy (small plaques). The remainder were slightly larger with decidedly turbid centres, similar to the wild-type plaque (large plaques). Bacteria in all small plaques and in a variable proportion of large plaques replicated to ampicillin agar, but low dilution plates (with many plaques) replicated to a greater extent than the number of plaques would warrant. This implied that the lysates also contained non-plaque-forming transducing elements. At higher dilutions of the phage lysates, the plaque-forming titre never exceeded the number of replica transductants. Colonies on the replica plates (replica transductants) were usually surrounded by a halo of smaller colonies. This was true for all individual plaques which replicated. Haloes are a feature of transductants produced by non-defective transducing phages lambda and $\phi 80$ (Matsushiro, Sato \& Kida, 1964), P22 


\section{Table 2. Transduction of markers of strain $\mathrm{PM} 5006(\mathrm{P}-$ lac $\overline{\mathrm{RP}}$ ) by phage $5006 \mathrm{M}$ to P. mirabilis PM5006}

Transductions were done as outlined in Methods. Adsorption was for $20 \mathrm{~min}$. For ampicillin resistance, membranes were incubated on nutrient agar for $3 \mathrm{~h}$ before transfer to MacConkey agar containing ampicillin at $30 \mu \mathrm{g} \mathrm{ml}^{-1}$. For detection of lactose utilization $\left(\mathrm{lac}^{+}\right)$, membranes were placed on lactose minimal medium directly after filtration.

$\begin{array}{ccccc}\text { M.o.i. } & \begin{array}{c}\text { Selected } \\ \text { marker }\end{array} & \begin{array}{c}\text { Transduction } \\ \text { frequency* }\end{array} & \begin{array}{c}\text { Properties of } \\ \text { transductants }\end{array} & \begin{array}{c}\text { transfer of } \\ \text { selected } \\ \text { marker }\end{array} \\ 3 & \mathrm{~A} & 5 \times 10^{-10} & \mathrm{~A} & \mathrm{O} / 5 \\ 0.2 & \mathrm{~A} & 5 \times 10^{-10} & \mathrm{~A} & \mathrm{O} / 5 \\ 3 & \mathrm{lac}^{+} & <\mathrm{I} \times 10^{-10} & \mathrm{NT} & \mathrm{NT} \\ 0.2 & \text { lac }^{+} & <3 \times 10^{-10} & \mathrm{NT} & \mathrm{NT}\end{array}$

M.o.i., multiplicity of infection; A, ampicillin resistance; NT, not tested.

* Transduction frequency per p.f.u. adsorbed.

$\dagger$ Recipient was $E$. coli $\mathrm{J} 62-\mathrm{I}$. The denominator indicates the number of clones tested.

(Jessop, 1972) and a high frequency defective transducing variant of $\mathrm{P} 22$ in the presence of helper phage (Smith-Keary, 1966). Phage in all the lysates transduced the ampicillin resistance marker to PM5006 at more or less equal frequencies and one of the lysate systems (no. 5) was chosen at random for further study. Phage in these lysates was named phage $5006 \mathrm{Mp} a$, though mindful of the fact that not all particles present were plaque-forming. The plaque-forming titre of this lysate was neutralized at a similar frequency to that of phage $5006 \mathrm{Msusk}\left(\mathrm{I} 70 \mathrm{~min}^{-1}\right.$ versus $\mathrm{I} 80 \mathrm{~min}^{-1}$ ) by phage antiserum and the phages were considered serologically identical.

\section{Transductions}

The transduction frequency of the ampicillin resistance marker varied with the multiplicity of infection (m.o.i.) of the transducing phage (Table 3, lines I, 2) but frequencies usually exceeded unity. In confirmation of the results of the replication experiments, this implied that non-plaque-forming phage particles could also transduce the marker. In experiments where phage antiserum was not used to prevent secondary infection on the plates, PM5006 transductants were usually surrounded by a halo of smaller colonies. Abortive transductants (Appelbaum et al., 1972; and see Coetzee, 1975c) were not encountered. Strain NHI adsorbed phage in the lysate as avidly as PM5006 and was transduced to ampicillin resistance (Table 3, line 8) at frequencies of $\mathrm{I} \times 1 \mathrm{I}^{-3}$ per p.f.u. adsorbed. Phage adsorption to strain PM804 could not be demonstrated (see Coetzee, I976a) but the ampicillin resistance marker was transduced to it with greater efficiency (Table 3, line 6) than were markers of the high frequency transducing phages previously described (Coetzee, $1976 a, b$ ). This was probably due to the higher transduction frequency (to PM5006) of the present phage lysate. The great transduction potential of the lysate was put to good effect when ampicillin-sensitive strains of Proteus previously tested for phage transduction (Coetzee, 1975c, 1976a) were again screened with the present phage. One strain, $P$. mirabilis PM98, yielded a few ampicillin-resistant transductants (Table 3, line 7). Again this organism could not be shown to adsorb the phage and no kanamycin- or streptomycin-resistant transductants were obtained using phage 5006MHFTsusk.

Phage present in the lysate was also capable of generalized transduction in that it would transduce various auxotrophs of PM5006 to prototrophy (Table 3, lines 3 to 5) at frequencies similar to those described for other specialized high frequency transducing phages (Coetzee, 
Table 3. Transduction of ampicillin resistance by phage $5006 \mathrm{Mp}$ a lysate to strains of $P$. mirabilis

Phage 5006Mpa lysate was obtained by ultraviolet induction of PM5006( $\overline{\mathrm{A}})$. Transductions were done as outlined in Methods and the legend to Table 2. For detection of prototrophy, membranes were placed on minimal medium directly after filtration.

\begin{tabular}{|c|c|c|c|c|}
\hline \multirow[b]{2}{*}{ Recipient } & \multirow{2}{*}{$\begin{array}{c}\text { M.o.i. or } \\
\text { m.i.* }\end{array}$} & \multicolumn{2}{|c|}{ or no. of transductants $\ddagger$} & \multirow{2}{*}{$\begin{array}{c}\text { transfer of } \\
\text { selected } \\
\text { marker } \dagger\end{array}$} \\
\hline & & $\mathbf{A}$ & Prototrophy & \\
\hline PM5006 & $x \cdot r$ & $3 \cdot I$ & NT & $0 / 5$ \\
\hline PM5006 & 0.05 & $I \cdot 2$ & NT & $0 / 5$ \\
\hline PM5006arg-I & $I \cdot I$ & $3 \cdot 2$ & $5 \times 10^{-9}$ & NT \\
\hline PM5006lys-I & $I \cdot \mathbf{I}$ & $3 \cdot 0$ & $5 \times 10^{-9}$ & NT \\
\hline PM5006trp-I & $I \cdot I$ & 3.7 & $5 \times 10^{-8}$ & NT \\
\hline PM804 & $\mathbf{I} \cdot \mathbf{2}^{*}$ & $39 \ddagger$ & NT & $0 / 5$ \\
\hline PM98 & $1 \cdot 2^{*}$ & IIf & NT & $0 / 5$ \\
\hline NHI & $1 \cdot 8$ & $1 \times 10^{-3}$ & NT & $0 / 5$ \\
\hline PM5006(SuSK $)$ & $\mathrm{I} \cdot 8$ & $54 \ddagger$ & NT & $0 / 5$ \\
\hline
\end{tabular}

A, ampicillin resistance; NT, not tested.

* Multiplicity input.

$\dagger$ Recipient was $E$. coli $\mathrm{J} 62-\mathrm{I}$. The denominator indicates the number of clones tested.

I974, I975a, I976b). Although adsorption of phage 5006MHFTsusk to PM5006 antibioticresistant transductants could not be demonstrated because of lysogenic conversion to homologous phage non-adsorption, phage 5006Mpa could overcome the barrier to some extent and produced a number of transductants (Table 3, line 9). The possibility that the association between plaque-formation and transduction to ampicillin resistance was caused by double infection with defective transducing and plaque-forming phage was unlikely since, at a multiplicity input of 0.000 I p.f.u. of the lysate, the bacterial growth of $100 \%$ of small plaques and that of only $13 \%$ of large plaques replicated to ampicillin agar. Small plaques constituted $92 \%$ of plaques.

Three of each type of plaque were picked off into saline, sterilized with chloroform and dilutions were plated with PM5006 (Table 4, lines I to 3). The cycles of growth produced marked changes in the incidence of the plaque-types. The progeny of the phage in the small plaques (Table 4 , lines 4 to 6 ) yielded a higher proportion of large plaques and whereas the growth in all small plaques replicated to ampicillin agar, only that of an average of I $\%$ of large plaques replicated to this medium. The progeny of the large plaque-forming particles (Table 4, lines 7 to 9) produced an even lower proportion of small plaques. The bacterial growth in none of the large plaques of the latter experiment replicated to ampicillin agar. It was concluded that the phage particles which initiated small plaques were ampicillinresistance transducing but unstable, and during plaque-formation could 'revert' (Jessop, I972) to wild-type phage.

\section{Helper effect}

The effect of non-transducing homologous helper phage on the transduction frequency was complicated by the fact (unpublished) that the reductive response to the prophage state is greater with multiple than with single infection. Raising the m.o.i. from 0.1 to 4 (Table 5, lines 2,3 ) nearly quadrupled the transduction frequency, but a similar effect was achieved by helper phage at an m.o.i. of 4 (Table 5, line 5); there were many more haloed transductants in the absence of helper phage. This could mean that the plaque-forming phage in the lysate did not inhibit its lytic response, even in multiple infection, to the same extent as 
Table 4. Stability of ampicillin resistance-phage 5006M association

Three independently induced lysates of PM5006( $\bar{\AA})$ were titrated on PM5006 and plates with wellseparated plaques were studied further. Three plaques of both morphologies were picked off into saline, treated with chloroform and replated with PM5006 at a multiplicity input $<0.001$.

Proportion and properties of plaque-types on PM5006

\begin{tabular}{|c|}
\hline 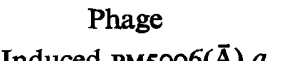 \\
\hline $\begin{array}{l}\text { Induced PM5006( }(\bar{A}) a \\
\text { Induced PM5006( }(\bar{A}) b \\
\text { Induced PM5006( } \bar{A}) c\end{array}$ \\
\hline $\begin{array}{l}\text { Small plaque I } \\
\text { Small plaque } 2 \\
\text { Small plaque } 3\end{array}$ \\
\hline $\begin{array}{l}\text { Large plaque } 1 \\
\text { Large plaque } 2 \\
\text { Large plaque } 3\end{array}$ \\
\hline
\end{tabular}

$\begin{array}{cc}\text { Small } & \text { Large } \\ 92(100)^{*} & 8(15) \\ 85(100) & 15(12) \\ 89(100) & 11(12) \\ 51(100) & 49(12) \\ 44(100) & 56(8) \\ 53(100) & 47(13) \\ 0(-) & 100(0) \\ \text { II (100) } & 89(0) \\ 21(100) & 79(0)\end{array}$

* Numbers in parentheses show the percentage of plaques which replicated to ampicillin agar.

\section{Table 5. Effect of phage $5006 \mathrm{M}$ on transduction frequency of ampicillin resistance to PM5006 by a phage 5006Mpa lysate}

Transductions were done as outlined in Methods and in the legend to Table 2.

$\begin{array}{cccc}\text { Phage m.o.i. } & \begin{array}{c}\text { Transduction } \\ \text { frequency* }\end{array} & \begin{array}{c}\text { Haloed } \\ \text { transductants } \\ (\%)\end{array} \\ 0 & \text { 5006M.PM5006 } & 0 & <\times 10^{-10} \\ 0 \cdot 1 & 4 \cdot 0 & 1 \cdot 3 & 56 \\ 4 \cdot 1 & 0 & 4 \cdot 8 & 91 \\ 4 \cdot 2 & 0 & 6 \cdot 3 & 18 \\ 0.2 & 4 \cdot 1 & 5 \cdot 1 & 26\end{array}$

* Transduction frequency per p.f.u. of phage 5006Mpa lysate adsorbed.

with the help of phage 5006M (see Jessop, 1972). On the other hand all transduction frequencies were greater than unity and mutual help between defective transducing particles or interaction between the latter and helper phage could distort the results. The nature of the defect in the non-plaque-forming phage particles was not determined.

\section{Properties of transductants}

The ampicillin resistance marker of independently isolated transductant clones could not be transferred to J62-I in mating experiments (Table 3). Transductants expressed resistance to ampicillin at $25 \mu \mathrm{g} \mathrm{ml}^{-1}$ after the $20 \mathrm{~min}$ allowed for phage adsorption and attained maximum resistance $\left(50 \mu \mathrm{g} \mathrm{ml}^{-1}\right)$ within $\mathrm{I} h$ after the adsorption period (Table 6). Transductants produced by single phage infection and reared in the presence of phage antiserum to prevent possible secondary infection, were all lysogenic in that, spontaneously and following u.v. induction, they liberated phage which had similar properties to the transducing lysate. Adsorption of phage 5006M could not be demonstrated due to lysogenic conversion to homologous phage non-adsorption (Coetzee, 1961, 1974; Krizsanovich, 1973). Overnight broth cultures of several independently isolated PM5006 transductants were plated on MacConkey agar to yield about 80 clones per plate after overnight incubation. When replicated to ampicillin agar, less than $5 \%$ of the colonies of each transductant grew. This implied a very high segregation frequency of the marker of transductants and was 
Table 6. Kinetics of transduction and expression of ampicillin resistance

Transduction conditions were as described in Methods and the legend to Table 2. Time o coincided with the end of the $20 \mathrm{~min}$ adsorption period. Membranes, with impinged cells, were kept on nutrient agar for the period indicated before transfer to ampicillin agar. Membranes were prepared in quadruplicate.

Incubation
period
(min)
0
30
60
120

No. of resistant transductants per plate with
ampicillin $\left(\mu \mathrm{g} \mathrm{ml}^{-1}\right):$

Table 7. Properties of transductants of P. mirabilis strains by a phage 5006Mpa lysate

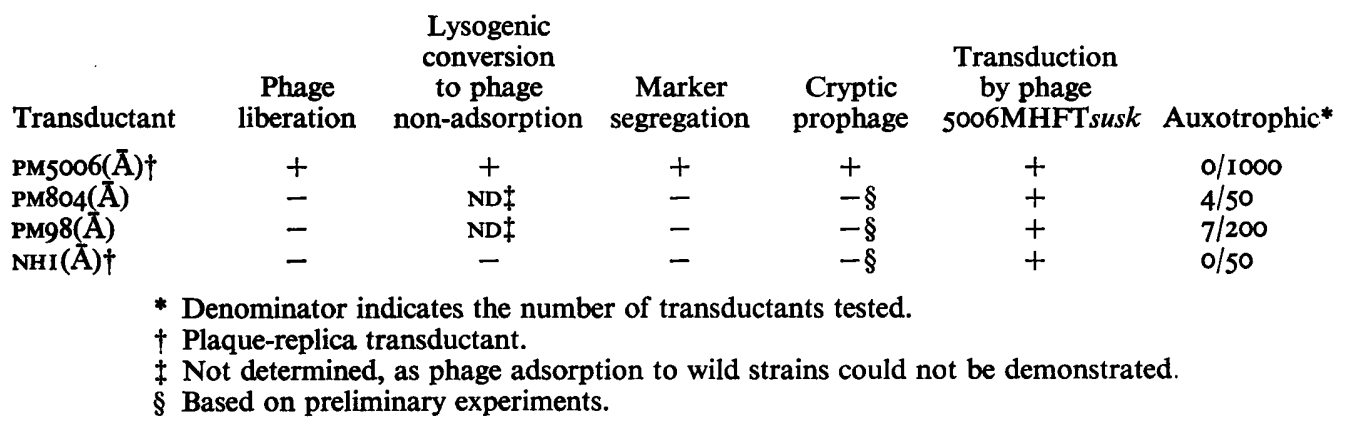

regarded as proof of their heterogenote-like nature. Despite failure to demonstrate adsorption of phage 5006M to PM5006 transductants, these ampicillin-resistant transductants could be transduced (in small numbers) to kanamycin and streptomycin resistance by phage 5006MHFTsusk just as primary transductants by the latter phage could be transduced to ampicillin resistance by phage 5006Mpa lysates (Table 3, line 9). This was further proof (see Coetzee, 1976b) that lysogenic conversion to homologous phage non-adsorption is not absolute. Phage 5006Mpa transductants of PM804, PM98 and plaque-replica transductants of NHI differed from those of PM5006 in that they did not liberate phage spontaneously or on u.v. induction.

PM804 and PM98 transductants could be transduced by phage 5006MHFTsusk in numbers, and NHI transductants at frequencies, comparable to the original transductions. For strain NHI transductants (where phage adsorption could be measured), plaque-replica transductants adsorbed phage 5006 Mpa lysates to the same extent as the parent organism. This pointed to a definite defect in phage 5006 Mpa in comparison with phage $5006 \mathrm{M}$ (see Coetzee, I976a,b). The ampicillin resistance marker of PM804 and PM98 transductants as well as NHI plaque-replica transductants was stable and no segregants were obtained. This contrasted with transductants of PM804 and NHI obtained with phages 5006MHFTak (Coetzee, I975a) and 5006MHFTsusk which segregated their markers freely. A summary of some of the properties of the transductants is given in Table 7 . 


\section{Translocation of the ampicillin marker to other replicons}

The phage 5006Mpa lysate was titrated on PM5006(RS-a) and the high dilution plates were replicated to ampicillin/chloramphenicol agar. Many plaque-replica transductants were obtained and, after purification on the same agar, a transductant was mated with J62-I. Selection was for transfer of ampicillin resistance. All of 24 transcipients examined had the complete resistance pattern of RS-a plus ampicillin resistance, and five out of five transferred these antibiotic resistances to PM5006 with counterselection of the donors with tetracycline. This result differed from those obtained by Hedges \& Jacob (1974) where the inserted ampicillin resistance marker inactivated the transfer genes of the RS-a plasmid. One thousand PM5006 ampicillin-resistant transductants produced at an m.o.i. of phage $5006 \mathrm{Mp} a$ of less than one, as well as 50, 50 and 200 transductants of PM804, NHI and PM98, respectively, and wild-type controls, were thoroughly washed and plated on minimal medium and MacConkey agar. All the PM5006 and NHI transductants grew as well as control cultures on minimal medium but $4(8 \%)$ transductants of PM804 and $7(3.5 \%)$ transductants of PM98 failed to grow on the minimal medium (Table 7). The growth requirements of two of the PM804 transductants were for lysine and proline respectively while those of four of the PM98 transductants were met by glycine, glycine, arginine and threonine respectively. The requirements of the remaining auxotrophs were not met by amino acids singly or in combination and remain undetermined. Working with a lambda phage which carried a kanamycin resistance transposon, Berg et al. (1975) found that about $\mathrm{I} \%$ of transductants had new growth requirements.

\section{DISCUSSION}

The principle of inducing a heterogenote-like transductant to obtain a lysate of phage bearing the particular gene was enunciated by Luria et al. (1960) and developed by Hoppe \& Roth (1974) and Rae \& Stodolsky (1974). Luria et al. (1960) prepared heterogenotes by transducing the lactose fermentation marker of Escherichia coli to a strain of Shigella. They were thus able to select for single crossover events (lysogenization) rather than the reciprocal double crossover associated with integration of homologous markers. Readily available sources of possibly non-homologous genes are antibiotic resistance determinants of various $R$ plasmids and a number (see Coetzee, $1976 b$ ) of phage lysates, able to transduce antibiotic resistance markers at high frequency, have been prepared in this way. The marker concerned here is the ampicillin resistance gene of plasmid RP4. Transposition of this ampicillin resistance marker to $\mathrm{R}$ factor R64 was originally reported by Datta et al. (197I). Richmond \& Sykes (1972) demonstrated that it could also move as a unit to the chromosome of $E$. coli. Hedges \& Jacob (1974) found that it comprised a $1 \cdot 7 \times 10^{6}$ to $3.9 \times 10^{6}$ dalton sequence of plasmid DNA and named this ampicillin resistance marker of RP4, transposon A (TnA). Kopecko \& Cohen (1975) and Heffron, Rubens \& Falkow (1975a) determined that TnA was bounded by inverted repeated sequences of about I 30 to I 40 nucleotides and Bennett \& Richmond (1976) proved that this ampicillin resistance marker could translocate between the chromosome of $E$. coli and a number of different R plasmids (see also Heffron et al., I975b). The ampicillin resistance converting phage, $\phi \mathrm{amp}$ (Williams Smith, I972), is thought to carry the same DNA sequence (Hedges et al., I974). Here the marker was moved to the plasmid P-lac (unpublished) and from there to phage 5006M which in turn could donate it to R factor RS-a and the chromosomes of $P$. mirabilis strains PM804 and PM98.

The fact that the transducing phage was liberated spontaneously from all PM5006 transductants and that none of 1000 transductants exhibited any other growth requirement, 
made the transposition of the marker from the transducing phage to the PM5006 chromosome unlikely because insertion into a gene could inactivate it by interruption of its continuity (Heffron et al., I975a; Hedges \& Jacob, 1974; Berg et al., 1975; Kleckner et al., 1975). On the other hand none of the transductants of PM804, PM98 or NHI liberated phage. This differed from previous results for PM804 (Coetzee, 1976a) in that transductants by phages 5006MHFT $k$ and 5006MHFTak liberated the corresponding transducing phages spontaneously and on u.v. induction, but agreed with findings for NHI transductants produced at low m.o.i. which also did not liberate phage. The present results are in agreement with those for phage 5006MHFTsusk transductants of PM804 which did not liberate phage (Coetzee, $1976 \mathrm{~b}$ ). In addition, $8 \%$ of PM804 and $3.5 \%$ of PM98 transductants failed to grow on minimal medium. Apart from indicating a possible defect in maturation of the phage it could mean that the ampicillin resistance marker in some PM804 and PM98 transductants was transposed to the host chromosome. This translocation could be accompanied by further lesions in the phage chromosome. The reason for the difference between PM5006 and NHI transductants and those of PM804 and PM98 is not known but it could be significant that a cryptic prophage 5006M has only been discovered in PM5006 (Krizsanovich, 1973; Coetzee, 1974). Unlike phage $\phi 80$ pt (Matsushiro et al., 1964), the marker was unstable during lytic growth and resembled phages $\lambda$ kan-3 (Berg et al., I975), $\lambda \mathrm{Cm}$ (Gottesman \& Rosner, 1975 ; Berg et al., 1975) and PrCM (Kondo \& Mitsuhashi, 1964, 1966) in this respect.

Other resistance determinants of $\mathrm{R}$ plasmids like tet (Kleckner et al., I975), kan (Berg et al., 1975) and cam (Gottesman \& Rosner, 1975) have been shown to translocate between different replicons. However, it is not known whether the ampicillin and kanamycin resistance markers of plasmid R394 (Coetzee, Datta \& Hedges, 1972), which combined with phage 5006M (Coetzee 1974, I975a) and phage PL25 (Coetzee, 1975 b), or the sulphonamide and streptomycin resistance markers of R905 (Hedges, I975), which also combined with the former phage (Coetzee, $1976 \mathrm{~b}$ ), are transposons. An argument against this possibility is that the resulting phage particles do not apparently show the mutual co-operative effect in transduction which would be expected from additions (rather than substitutions) to the permuted phage genomes (Coetzee, 1976b; Chan et al., 1972; Tye et al., 1974; Kleckner et al., 1975; Rae \& Stodolsky, 1974; Van Rensburg, 1970). The fact that repeated attempts have failed (unpublished) to isolate plaque-forming transducing variants of the Proteus and Providence high frequency transducing phages could possibly also be regarded as favouring a substitution event.

Deletions of portions of DNA not necessarily contiguous with DNA insertions have been described (Manley, Signer \& Radding, 1969; Starlinger \& Saedler, 1972; Lee et al., 1974; Kopecko \& Cohen, 1975; Ahmed \& Johansen, 1975; Cabezón et al., 1975; Reif \& Saedler, 1975; Dempsey \& Willetts, 1976, and see Starlinger \& Saedler, 1976). The tentative model favoured to account for a lysate containing both plaque and non-plaque-forming phage particles is that transposition of the ampicillin resistance marker to the phage $5006 \mathrm{M}$ genome could be accompanied (or followed) by deletion of non-essential portions of the phage chromosome (Manly et al., 1969). The latter genome could be encapsidated and would constitute plaque-forming transducing variants defective in phage conversion to homologous phage non-adsorption, in reduction steps to prophage (and hence the enhancing effect on lysogenization and the transduction frequency of the wild-type phage 5006M) and possibly also in phage maturation. These defects could account for the altered plaque morphology produced by the transducing phage particles. Those genomes not suffering deletions were oversized and would be fragmented during encapsidation (Chan et al., 1972) and account for the population of defective non-plaque-forming transducing phage. The 
fact that only low dilution phage titration plates gave more replica transductants than was accounted for by plaque count, could signify mutual aid between defective phage particles (Chan et al., 1972).

Only one of the five original phage lysates was studied further because preliminary work suggested that they were similar. Further studies could, however, reveal differences between individual lysates as encountered by Berg et al. (1975) for stability of the marker during lytic growth of the $\lambda$ pkan phages, and by Gottesman \& Rosner (1975) with regard to the site of insertion_of the chloramphenicol resistance marker into the lambda chromosome to yield $\lambda$ pcam transducing phages.

The author is in receipt of grants from the South African Medical Research Council.

\section{REFERENCES}

ADAMS, M. H. (1956). Methods of study of bacterial viruses. Methods in Medical Research $2, \mathrm{I}-73$.

AHMED, A. \& JoHANSEN, E. (1975). Reversion of the gal3 mutation of Escherichia coli: partial deletion of the insertion sequence. Molecular and General Genetics 142, 263-275.

Appelbaum, P. C., Trichardt, P. F., Krizsanovich, K. \& Coetzee, J. N. (1972). Abortive transduction of mobility in Proteus and Providence strains. Journal of General Microbiology 70, 36I-364.

BENNETT, P. M. \& RICHMOND, M. H. (I976). Translocation of a discrete piece of deoxyribonucleic acid carrying an amp gene between replicons in Escherichia coli. Journal of Bacteriology 126, I-16.

Berg, D. E., Davies, J., Allet, B. \& Rochaix, J. D. (1975). Transposition of R factor genes to bacteriophage $\lambda$. Proceedings of the National Academy of Sciences of the United States of America 72, 3628-3632.

Cabezón, T., Faelen, M., De Wilde, M., Bollen, A. \& Thomas, R. (1975). Expression of ribosomal protein genes in Escherichia coli. Molecular and General Genetics 137, 125-1 29.

Chan, R. K., Botstein, D., Watanabe, T. \& OGata, Y. (1972). Specialized transduction of tetracycline resistance by phage $P_{22}$ in Salmonella typhimurium. Virology 50, 883-898.

Chesney, R. H. \& ScotT, J. R. (1975). Superinfection immunity and prophage repression in phage PI. II. Mapping of the immunity-difference and ampicillin-resistance loci of PI and $\phi$ amp. Virology 67, 375-384.

Clowes, R. C. \& HAYes, W. (1968). Experiments in Microbial Genetics. Oxford and Edinburgh: Blackwell Scientific Publications.

Coetzee, J. N. (196I). Lysogenic conversion in the genus Proteus. Nature, London 189, 946-947.

COETZEE, J. N. (I974). High frequency transduction of kanamycin resistance in Proteus mirabilis. Journal of General Microbiology 84, 285-296.

CoetzeE, J. N. (I975a). High frequency transduction of ampicillin and kanamycin resistance in Proteus mirabilis. Journal of General Microbiology 87, 173-176.

Coetzee, J. N. (1975b). Specialized transduction of kanamycin resistance in a Providence strain. Journal of General Microbiology 88, 307-316.

Coetzee, J. N. (1975c). Transduction of a Proteus vulgaris strain by a $P$. mirabilis bacteriophage. Journal of General Microbiology 89, 299-309.

Coetzee, J. N. (1976a). Intra-species transduction with Proteus mirabilis high frequency transducing phages. Journal of General Microbiology 93, I 53-165.

CoetzeE, J. N. (1976b). Derivation and properties of Proteus mirabilis systems for high frequency transduction of streptomycin-sulphonamide and streptomycin-sulphonamide-kanamycin resistances. Journal of General Microbiology 96, 95-107.

CoetzeE, J. N. \& SACKS, T. G. (I960). Transduction of streptomycin resistance in Proteus mirabilis. Journal of General Microbiology 23, 445-455.

CoetzeE, J. N. \& SMIT, J. A. (I969). Restriction of a transducing bacteriophage in a strain of Proteus mirabilis. Journal of General Virology 4, 593-607.

Coetzee, J. N. \& Smit, J. A. (1970). Properties of Proteus mirabilis phage 13vir. Journal of General Virology 9, 247-249.

Coetzee, J. N., Datta, N. \& Hedges, R. W. (1972). R factors from Proteus rettgeri. Journal of General Microbiology 72, 543-552.

Coetzee, J. N., Datta, N., Hedges, R. W. \& Appelbaum, P. C. (1973). Transduction of R factors in Proteus mirabilis and P. rettgeri. Journal of General Microbiology 76, 355-368.

DATTA, N. \& HEDGes, R. W. (1972). Host ranges of R factors. Journal of General Microbiology 70, 453-460.

Datta, N., Hedges, R. W., Shaw, E. J., Sykes, R. B. \& Richmond, M. H. (I97I). Properties of an R factor from Pseudomonas aeruginosa. Journal of Bacteriology 108, 1 $244-1249$. 
Dempsey, W. B. \& WilletTs, N. S. (1976). Plasmid co-integrates of prophage lambda and R factor 100. Journal of Bacteriology 126, $166-176$.

Dubnau, E. \& Stocker, B. A. D. (1964). Genetics of plasmids in Salmonella typhimurium. Nature, London 204, II I 2-1 II 3 .

Falkow, W., Wohlhieter, J. A., Citarella, R. V. \& Baron, L. S. (1964). Transfer of episomic elements to Proteus. Journal of Bacteriology 88, I598-I60I.

Goldberg, R. B., Bender, R. A. \& Streicher, S. L. (1974). Direct selection for Pi-sensitive mutants of enteric bacteria. Journal of Bacteriology II8, 810-814.

GotTesman, M. M. \& Rosner, J. L. (1975). Acquisition of a determinant for chloramphenicol resistance by coliphage lambda. Proceedings of the National Academy of Sciences of the United States of America 72, 5041-5045.

Grabow, W. O. K. (1972). Growth-inhibiting metabolities of Proteus mirabilis. Journal of Medical Microbiology 5, 191-196.

Grabow, W. O. K. \& SMIT, J. A. (1967). Methionine synthesis in Proteus mirabilis. Journal of General Microbiology 46, 47-57.

Hedges, R. W. (1975). R factors from Proteus mirabilis and P. vulgaris. Journal of General Microbiology 87 , 30I-3II.

Hedges, R. W. \& JACOB, A. E. (1974). Transposition of ampicillin resistance from RP4 to other replicons. Molecular and General Genetics 132, 31-40.

Hedges, R. W., Datta, N., Kontomichalou, P. \& Smith, J. T. (1974). Molecular specificities of R factordetermined beta-lactamases: correlation with plasmid compatibility. Journal of Bacteriology II7, 56-62.

HefFron, F., RubENS, C. \& FALKow, S. (1975a). Translocation of a plasmid DNA sequence which mediates ampicillin resistance: molecular nature and specificity of insertion. Proceedings of the National Academy of Sciences of the United States of America 72, 3623-3672.

Hefrron, F., Sublett, R., Hedges, R. W., Jacob, A. \& Falkow, S. (1975 $b$ ). Origin of the TEM betalactamase gene found on plasmids. Journal of Bacteriology 122, 250-256.

Hoppe, I. \& ROTH, J. (1974). Specialized transducing phages derived from Salmonella phage P22. Genetics 76, 633-654.

Jessop, A. P. (1972). A specialized transducing phage of $\mathrm{P}_{22}$ for which the ability to form plaques is associated with transduction of the proAB region. Molecular and General Genetics 114, 214-222.

Kameda, M., Harada, K., Suzuki, M. \& MitsuHashi, S. (1965). Drug resistance of enteric bacteria. V. High frequency of transduction of $\mathrm{R}$ factors with bacteriophage epsilon. Journal of Bacteriology 90 , I I 74-II8I.

KLeCkner, N., Chan, R. K., Tye, B. K. \& Botstein, D. (1975). Mutagenesis by insertion of a drug-resistance element carrying an inverted repetition. Journal of Molecular Biology 97, 56I-575.

KonDO, E. \& MrTsuHAshi, S. (1964). Drug resistance of enteric bacteria. IV. Active transducing bacteriophage PICM produced by the combination of R factor with bacteriophage PI. Journal of Bacteriology 88, $1266-1276$.

KoNDO, E. \& MITSUHASH, S. (I966). Drug resistance of enteric bacteria. VI. Introduction of bacteriophage PICM into Salmonella typhi and formation of PIdCM and F-CM elements. Journal of Bacteriology 9r, I 787-1 794 .

Kopecko, D. J. \& CoHEN, S. N. (1975). Site specific recA-independent recombination between bacterial plasmids: involvement of palindromes at the recombinational loci. Proceedings of the National Academy of Sciences of the United States of America 72, $1373-1377$.

KRIZSANOVICH, K. (1973). Cryptic lysogeny in Proteus mirabilis. Journal of General Virology 19, 31 1-320.

LeE, H. J., Ohtsubo, E., Deonier, R. C. \& DAvidson, N. (1974). Electron microscope heteroduplex studies of sequence relations among plasmids of Escherichia coli V. ilv $v^{+}$deletion mutants of Fi4. Journal of Molecular Biology 89, 585-597.

Luria, S. E., ADAMS, J. N. \& TING, R. C. (1960). Transduction of lactose-utilizing ability among strains of $E$. coli and $S$. dysenteriae and the properties of the transducing phage particles. Virology 12, 348-390.

MANLY, K. F., SigneR, E. R. \& RADDING, C. M. (1969). Nonessential functions of bacteriophage $\lambda$. Virology 37, $177-188$.

Matsushiro, A., SATo, K. \& KIDA, S. (1964). Characteristics of the transducing elements of bacteriophage $\phi 80$. Virology 23, 299-306.

RaE, M. E. \& Stodolsky, M. (1974). Chromosome breakage, fusion and reconstruction during PI $d l$ transduction. Virology $58,32-54$.

REIF, H. J. \& SAEDLER, H. (I975). IsI is involved in deletion formation in the gal region of E. coli KI2. Molecular and General Genetics 137, 17-28.

Richmond, M. H. \& SYKeS, R. B. (I972). The chromosomal integration of a lactamase gene derived from the P-type R factor RPI in Escherichia coli. Genetical Research 20, 23 I-237.

ScotT, J. R. (I973). Phage PI cryptic. II. Location and regulation of prophage genes. Virology 53, 327-336.

Smith-KeARY, P. F. (1966). Restricted transduction by bacteriophage P22 in Salmonella typhimurium. Genetical Research, Cambridge 8, 73-82.

Starlinger, P. \& SAedleR, H. (1972). Insertion mutations in micro-organisms. Biochimie 54, $177-185$. 
Starlinger, P. \& SAedler, H. (1970). IS-elements in microorganisms. Current Topics in Microbiology and Immunology (in the Press).

TYE, B. K., ChAN, R. K. \& Botstein, D. (1974). Packaging of an oversize transducing genome by Salmonella phage P22. Journal of Molecular Biology 85, 485-500.

VAn Rensburg, A. J. (1970). Studies on Proteus and Providence spheroplasts, L-forms and bacteriophage nucleic acids. M.D. thesis, University of Pretoria, South Africa.

Watanabe, T., Ogata, Y., Chan, R. K. \& Botstein, D. (1972). Specialized transduction of tetracycline resistance by phage $\mathbf{P}_{22}$ in Salmonella typhimurium. I. Transduction of R factor 222 by phage $\mathbf{P 2 2}$. Virology 50, 874-882.

Williams Smith, H. (1972). Ampicillin resistance in Escherichia coli by phage infection. Nature, London 238, 205-206.

YAMAMOTO, K. R. \& ALBERTs, B. M. (1970). Rapid bacteriophage sedimentation in the presence of polyethylene glycol and its application to large-scale virus purification. Virology 40, 734-744. 